\title{
Aproximaciones al proceso de patrimonialización del territorio: Caso del sitio arqueológico Aypate (2012-2016)
}

\author{
Approaches of the patrimonialization process of the territory: Case of the \\ Aypate archaeological site (2012-2016)
}

\section{Abordagens ao processo de patrimonialização do território: Caso do sítio arqueológico de Aypate (2012-2016)}

\author{
Jessica Morán-Jorquera ${ }^{1}$ \\ Universidad Nacional Mayor de San Marcos \\ jessica.moran@unmsm.edu.pe \\ https://orcid.org/0000-0002-7528-2335
}

\begin{abstract}
RESUMEN
Un territorio rico en recursos naturales, principalmente de fuentes de agua, además de un exuberante verde que esconde en sus entrañas un centro religioso y administrativo inca.

La provincia de Ayabaca en Piura es un lugar que contradictoriamente, a pesar de la gran riqueza natural y cultural que posee, se caracteriza por la pobreza y falta de servicios básicos.

El presente trabajo comprende un acercamiento al proceso de patrimonialización que ha sufrido este territorio, proceso que amenaza la economía de subsistencia de las comunidades y rondas campesinas. Así mismo, se exponen algunas luces de cómo podría mejorar este proceso mediante una gestión participativa.
\end{abstract}

\begin{abstract}
A rich territory in natural resources, mainly water sources, in addition to a lush green that hides in its gut an Inca religious and administrative center.

The province of Ayabaca in Piura is a place that despite its great natural and cultural wealth is characterized by poverty and lack of basic services.

The present work includes an approach of the patrimonialization process that this territory has undergone, a process that threatens the subsistence economy of the communities and peasants. Likewise, some lights are presented on how this process could be improved through a participatory management.
\end{abstract}

\section{RESUMO}

Um território rico em recursos naturais, principalmente fontes de água, além de um verde exuberante que esconde em suas entranhas um centro religioso e administrativo inca.

1 Licenciada en Antropología de la Universidad Nacional Mayor de San Marcos, especialista en gestión participativa y presidenta del Centro de Estudios Sociales Aplicados.

Recibido:29/04/2020 - Aceptado: 31/07/2020 - Publicado: 22/02/2021

Citar como:

Morán-Jorquera, J. (2020). Aproximaciones al proceso de patrimonialización del territorio: Caso del sitio arqueológico Aypate (2012-2016). Espiral, revista de geografías y ciencias sociales, 2(4), 107 - 118. http://dx.doi.org/10.15381/espiral. v2i4.17736

C Los autores. Este artículo es publicado por Espiral, revista de geografías y ciencias sociales de la Universidad Nacional Mayor de San Marcos. Este es un artículo de acceso abierto, distribuido bajo los términos de la licencia Creative Commons Atribucion- No Comercia_Compartir Igual 4.0 Internacional. (http://creativecommons.org/licenses/by-nc-sa/4.0/) que permite el uso no comercial, distribución y reproducción en cualquier medio, siempre que la obra original sea debidamente citada. 
A província de Ayabaca em Piura é um lugar contraditório que, apesar de sua grande riqueza natural e cultural, se caracteriza pela pobreza e pela falta de serviços básicos.

Este trabalho inclui uma abordagem do processo de patrimonialização que este território tem sofrido, processo que ameaça a economia de subsistência das comunidades e o patrulhamento camponês. Da mesma forma, algumas luzes são expostas sobre como esse processo pode ser melhorado por meio da gestão participativa.

PALABRAS CLAVE: Proceso de patrimonialización; pobreza; gestión participativa; Ayabaca.

KEYWORDS: Patrimonialization process; poverty; participatory management; Ayabaca.

PALAVRAS-CHAVE: Processo de patrimonialização; pobreza; gestão participativa; Ayabaca.

\section{Introducción}

El presente artículo es resultado de una investigación mayor que profundiza los procesos participativos en la gestión del patrimonio cultural, específicamente en la gestión del Qhapaq Nan (camino inca), y se considera importante porque es un acercamiento que llama a entender los desafíos del proceso de patrimonialización sobre todo en nuestra sociedad.

Una sociedad que no conoce su pasado, por lo mismo que hubo un corte en su continuidad histórica e incluso más grave que rechaza parte de esta historia por temor a la discriminación. Ser discriminado tanto por los mismos pares, autoridades, agentes extraterritoriales, como lo son los agentes patrimonialistas.

Este trabajo pretende mostrar el contexto social de Ayabaca y el proceso de patrimonialización de dicho territorio. Además, brinda un breve análisis de medidas que intentan redefinir estos procesos de una manera participativa.

Las estrategias de investigación que fueron empleadas para recoger y analizar dicha realidad se llevaron a cabo en los años 2014 al 2017, teniendo como escenario a la provincia de Ayabaca, departamento de Piura.

Este trabajo cuenta con un enfoque cualitativo, puesto que pretende comprender la perspectiva de los actores acerca de los fenómenos que los rodea, es decir la forma en que los actores perciben subjetivamente su realidad. (Hernández, Fernández, Baptista, 2010)

Del mismo modo, es un trabajo de tipo aplicado, puesto que se encuentra dentro de los diseños de investigación-acción debido a que busca resolver problemas cotidianos e inmediatos y mejorar prácticas concretas. (Hernández, Fernández, Baptista, 2010)

Para ello, se ha revisado documentación tanto legal como administrativa con la finalidad de conocer mejor la historia de una manera cronológica. Igualmente, se han rescatado diversas entrevistas realizadas por la suscrita a autoridades comunales y población de la provincia de Ayabaca en trabajo de campo, para contar con las voces de los involucrados en este proceso.

\section{El sitio arqueológico Aypate: contexto social}

En la sierra de la región de Piura, se ubica la provincia de Ayabaca un territorio que se caracteriza por sus servicios ambientales hidrológicos, en parte por la presencia de la cuenca del Río Chira que se halla en las partes altas de la provincia, una cuenca de régimen continuo y de los más caudalosos de la costa. Además, considerada como una de las cuencas de mayor provisión de agua para la región². 
Igualmente, la provincia de Ayabaca cuenta con bosques de neblina y humedales altoandinos como páramos de gran capacidad de almacenamiento de agua, que guardan una increíble biodiversidad, y en ese hermoso paisaje que caracteriza a los bosques de neblina, entre ese exuberante verde, el Imperio Inca construyó un centro religioso y administrativo, que ocupa gran parte del cerro Aypate.

El centro religioso y administrativo Aypate, ubicado en el cerro que lleva el mismo nombre, se ubica aproximadamente en los $2.700 \mathrm{~m}$ s.n.m. y comprende edificaciones estatales que caracterizan a los centros provinciales incas como: plaza, acllawuasi, kallanka y ushnu (Astuhuamán, 2013) (Ver Figura 1).

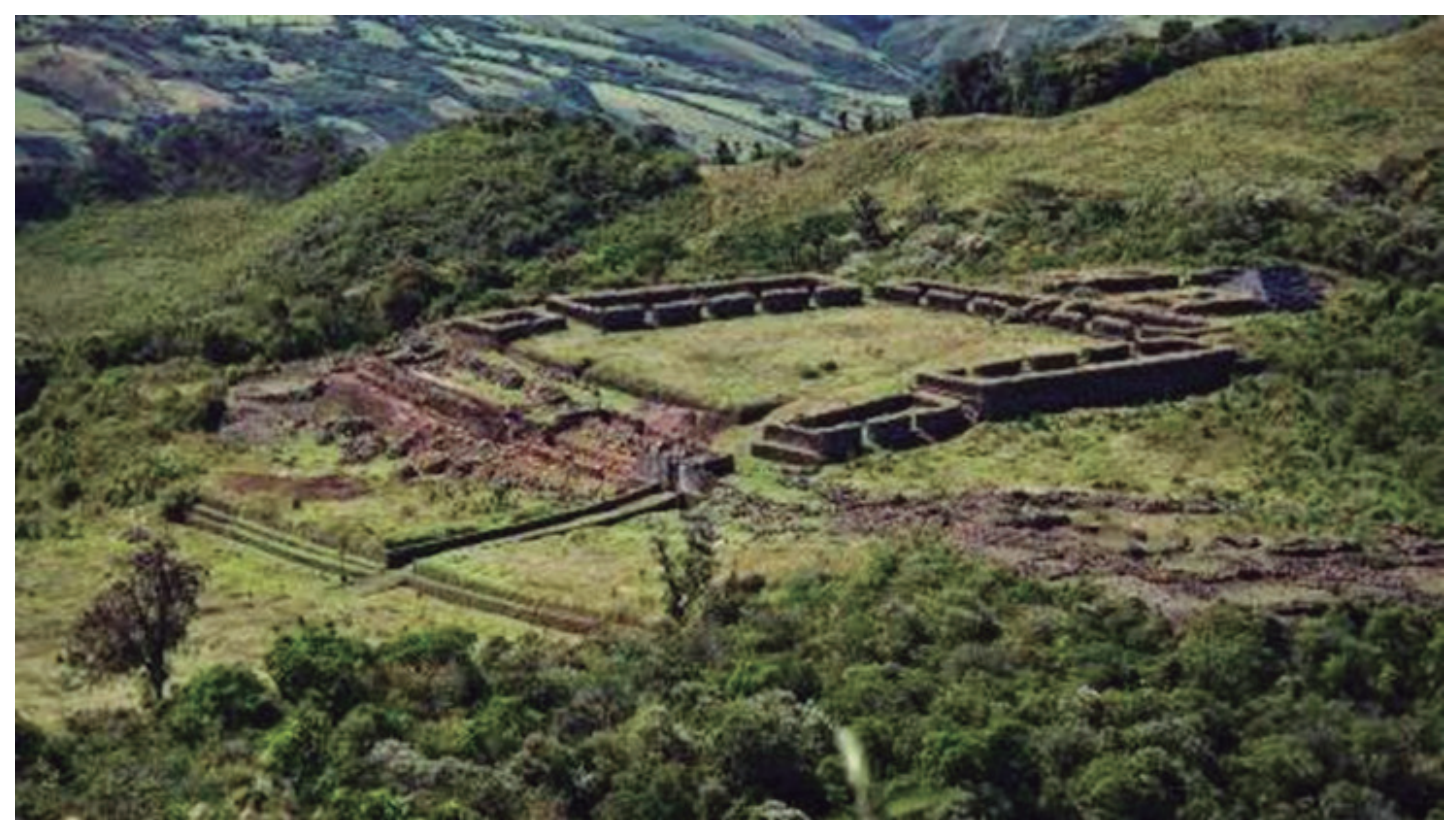

Figura 1. Vista panorámica del sitio arqueológico Aypate

Fuente: PQÑ (s.f.)

Entre tanta riqueza natural y cultural se encuentra una población de 119.287 habitantes a nivel provincial. Población a la que más del $65 \%$ se ve afecta por la pobreza, en donde más del $50 \%$ de los menores de 5 años sufre de desnutrición crónica y el 86,1 $\%$ de la población no cuenta con acceso a la red pública de desagüe dentro de la vivienda. (INEI, 2017)

Específicamente, el distrito de Ayabaca comprende 236 centros poblados rurales y 1 centro poblado urbano, 18 predios y 21 comunidades campesinas ${ }^{3}$. Los límites del distrito son por el Norte con el país de Ecuador, por el Sur con el distrito de Pacaipampa, por el Este nuevamente con Ecuador y por el Oeste con el distrito de Lagunas y distrito Sicchez (Ver Figura 2).

A nivel distrital, el nivel de instrucción del 57\% de las y los jefes de familia apenas alcanza a completar el nivel primario de educación básica regular y $29,6 \%$, algún año de educación secundaria, el porcentaje más bajo de la región. Además, el 17\% de la población no cuenta con ningún grado de instrucción. (INEI, 2018)

El 60\% de la producción es para el autoconsumo, la población se dedica básicamente al cultivo de alimentos para el consumo familiar. Los cultivos más importantes de la agricultura de subsistencia son: cebada, grano, maíz amiláceo, haba, grano seco, oca, trigo, papa, maíz, choclo y yuca. (INEI, 2018)

3 Municipalidad Provincial de Ayabaca, 2012. 


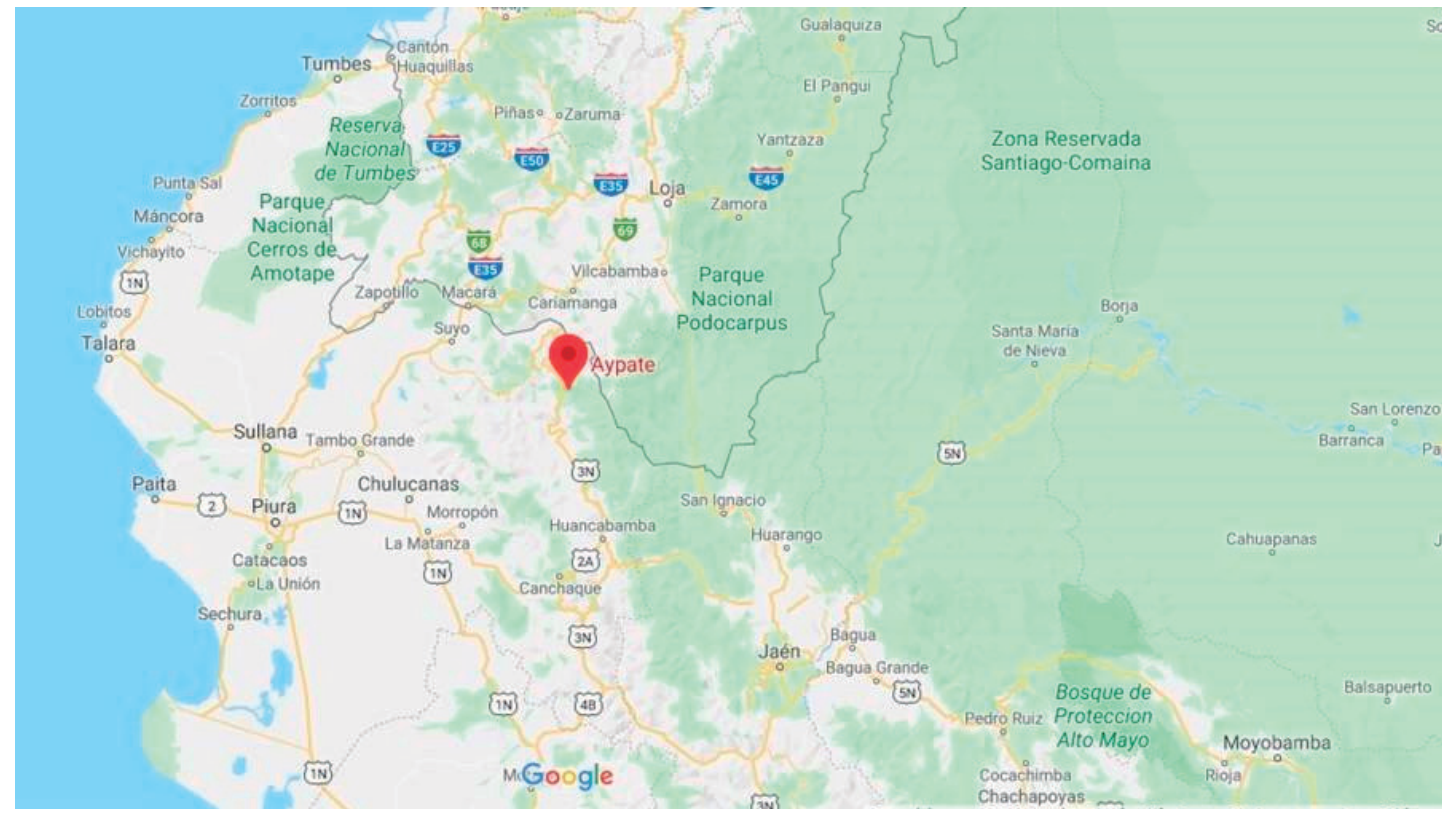

Figura 2. Ubicación geográfica del sitio arqueológico Aypate.

Fuente: Google (s.f.)

Ante estos datos se puede señalar que el sitio arqueológico Aypate está inserto en una zona caracterizada por la vulnerabilidad social, en el que la población, según testimonios de los propios pobladores, tiene una posición beligerante con respecto al Estado, en parte por sentirse permanentemente olvidada.

Asimismo, hay una especial oposición hacia los grandes proyectos de desarrollo porque piensan que van a despojarlos de sus tierras. En un ambiente así, es muy difíicil lograr la participación de las poblaciones en iniciativas que son ajenas a ellas. En la provincia de Ayabaca, las comunidades y sus rondas campesinas son la base de la organización social que define el manejo del territorio. Reconociendo esta realidad, el Proyecto Qhapaq Nan inició un paciente trabajo de acercamiento a tales organizaciones, sometiéndose a los procesos locales de toma de decisiones en las asambleas comunales y ronderas para lograr el compromiso de participación (...). (Marcone E Ruiz, 2014, p. 115)

Como bien señala Marcone y Ruiz (2014) la población vinculada al sitio arqueológico presenta múltiples necesidades. Sin embargo, cuenta con una organización social bien estructurada a nivel comunal, puesto que las comunidades y rondas campesinas de la provincia de Ayabaca cuentan con dos organizaciones que agrupan a las 76 comunidades campesinas que se encuentran en la provincia, que son la Federación Provincial de Comunidades Campesinas de Ayabaca (FEPROCCA) y el Comité Ejecutivo Provincial de Rondas Campesinas. Estas organizaciones articulan a diversos actores comunales y provinciales, además permite desarrollar iniciativas colectivas para el manejo del territorio.

Ahora, ¿qué opina esta población sobre el proceso de patrimonialización de su territorio? Territorio declarado Patrimonio Cultural de la Nación y posteriormente, inscrito a la Lista de Patrimonio Mundial de la Unesco como sitio vinculado a la red vial prehispánica llamada Qhapaq Nan.

\section{Proceso de patrimonialización del territorio}

El temprano proceso de patrimonialización del sitio arqueológico Aypate inició en el año 1989, cuando el Instituto Nacional de Cultura (INC) emitió la Resolución N²47-89/INC, la cual declara a Aypate como Patrimonio Cultural de la Nación y con 
ello se le dio la condición de intangibilidad, inalienabilidad e imprescriptibilidad a 156.061 hectáreas del territorio.

Luego de la declaratoria como Patrimonio Cultural de la Nación no se implementó una intervención continua en la zona arqueológica. Sin embargo, después de más de 20 años, se lleva a cabo el Proyecto de Investigación Arqueológica de Aypate, ejecutado por el Proyecto Qhapaq Ñan (PQÑ) del Ministerio de Cultura de Perú.

El programa oficial de acciones enfocadas hacia el Qhapaq Nan, hoy adscrito al Ministerio de Cultura, inicio en el año 2001 con el Decreto Supremo Nº31-2001-ED y posteriormente con la Ley $\mathrm{N}^{\circ} 28260$ promulgada el 28 de junio de 2004, que declara de "interés nacional la investigación, identificación, registro, protección, conservación y puesta en valor de la red de caminos existentes en el Imperio Incaico dentro del territorio peruano".

Este marco legal permite desarrollar una intervención sin etapas fijas, en un periodo de tiempo indeterminado. Las intervenciones del Proyecto Qhapaq Nan en un territorio específico son llamadas: (i) Proyectos Integrales, cuando se trata de un sitio arqueológico vinculado al camino inca, y (ii) Proyectos de Tramo, cuando se trata de una sección de camino, según el Plan Cuatrienal 2012-2015.

Para el año 2002 se inician las llamadas campañas de levantamiento de información del Sistema Vial Inca (Qhapaq Nan) al cual se incluye la zona arqueológica Aypate por estar vinculado a la red vial, y recién para el año 2012 se intenta llevar a cabo una intervención intensiva en el sitio.

Se dice "intenta" porque como bien se señaló líneas arriba, existe rechazo por la presencia de actores extraterritoriales, según las entrevistas realizadas se reconocen tres circunstancias que podrían justificar dicho comportamiento.

Primero, porque la intervención del arqueólogo italiano Mario Polia, reconocido por liderar en 1971 el descubrimiento científico de Aypate, según testimonios de pobladores, generó pasivos. Segundo, la declaratoria como Patrimonio Cultural de la Nación que se decretó sin la participación de la población y tercero; por el conflicto socioambiental causado por la Empresa Minera Río Blanco que, si bien su zona de intervención directa es en la provincia de Huancabamba ${ }^{4}$, las rondas campesinas de Ayabaca y la Federación Provincial de comunidades campesinas de Ayabaca se sumaron al rechazo de la actividad minera.

Las dos primeras son acciones dentro del proceso de patrimonialización, en el cual la población se reconoce como engañada por parte de las autoridades y profesionales representantes del Estado. A continuación, se presentan dos testimonios de autoridades comunales, quienes explican mejor la primera circunstancia:

También ha habido problemas más antes con el arqueólogo Mario Polia que ha ido saqueando todas las comunidades. Él supuestamente tenía autorización en ese tiempo por el Instituto Nacional de Cultura (...) Después de una reunión de rondas que tuvimos, nos informaron que él estaba saqueando al costado no más del local de la ronda. Entonces pues, paralizamos la reunión y entonces hemos ido a conversar con él y había una excavación de 6 metros. Ya había encontrado una cadena de oro y él se comprometió a traer al museo de Ayabaca. (Testimonio recogido en el año 2016, representante de Ayabaca)

Entonces esa persona, Mario Polia estuvo también en Aypate con conjunto con una señora de aquí de Ayabaca cuando recién se intervino las organizaciones, las comunidades le pusieron un alto. Es alli recién decide irse. (...) De alli se nos escapó. Se ha ido por Ecuador seguro donde no tenemos conocimiento, dejó durmiendo a los ronderos. (Testimonio recogido en el año 2016, representante de Olleros)

4 La provincia de Huancabamba se encuentra contigua a la provincia de Ayabaca. 
Igualmente, con respecto a la segunda circunstancia se presenta otro testimonio que señala como la declaratoria de Patrimonio Cultural de la Nación del sitio arqueológico Aypate, se decretó sin la participación de la población.

Hace tiempo cuando era INC actuaba de esa forma. Sin consulta a las comunidades, imponía y listo, eso era lo que sucedía. Cuando ponían su sitio, esa área poligonal, sin consentimiento, sin permiso de las comunidades. En ese tiempo el INC que se conoce y saben pusieron su sitio, su siniestro. Sin tener un permiso de la comunidad. (Testimonio recogido en el año 2016, representante de FEPROCCA)

Por último, la tercera circunstancia, la actividad minera en la zona, la cual es relacionada a la actividad arqueológica, puesto que en ambas actividades se debe excavar y la población tema que se analice la tierra para ver si hay metales en la zona, porque según los testimonios recogidos no se comprende porque tomaba tanto tiempo la investigación arqueológica.

Tanta plata que se gastan, a nosotros nos dan la mitad de plata y levantamos todo Aypate. (...) Ahora, está que se cae, gastan tan plata si se está cayendo, está lleno todo de palos para aguantar las piedras. (Testimonio recogido en el año 2014, representante de Tacalpo)

Estas tres circunstancias, las cuales se refuerzan con los testimonios presentados, justificarían dicho rechazo. Ahora, antes de continuar, saldría preguntar: ¿A qué llamamos proceso de patrimonialización?

Ascencio señala que la patrimonialización es una tendencia defensiva que busca preservar sitios arqueológicos y que cada vez se crean más categorías patrimoniales como expresiones inmateriales, paisajes, productos bioculturales y otros (Asensio, 2013). Específicamente en el caso del Perú, señala lo siguiente:

Ahora bien, en el Perú todos estos cambios se dan de una manera particular, que tiene que ver con la historia de la arqueología en el país. En concreto, podemos hablar de dos momentos. Desde aproximadamente 1910 asistimos a la consolidación de una alianza entre Estado y arqueólogos, cuyo resultado es los que podríamos llamar un "pacto patrimonialista" basado en dos principios: el monopolio del Estado en la propiedad y uso de los monumentos prehispánicos y el monopolio de los arqueólogos, convertidos en agentes estatales, sobre la manipulación e interpretación de los restos prehispánicos. La sintesis de estos dos principios se debe a Tello, que es quien realmente pone en marcha el actual modelo patrimonialista peruano, promoviendo las primeras leyes en este campo, en su condición de congresista, y modelando el papel de los arqueólogos como funcionarios al servicio del Estado. (Asensio, 2013, p. 26)

Así mismo, Asensio indica que en este "pacto patrimonialista", el Estado y el arqueólogo se convierten en agentes patrimonialistas y que los restos prehispánicos pasan a ser vistos como "patrimonio", provocando "la deslegitimación del vínculo entre las poblaciones locales y los monumentos prehispánicos" (Asensio, 2013), que ciertamente es lo que sucedió en la provincia de Ayabaca con Aypate.

A medida que se descubren nuevos valores del patrimonio cultural, (...) el patrimonio se nos representa como un factor clave para la ordenación del espacio y el desarrollo territorial, pues a estas alturas es indudable la dimensión territorial que tiene el patrimonio, pensemos no solo en el patrimonio construido sino también en el legado de las grandes ciudades como expresión de un urbanismo cultural y de otras estructuras territoriales como son las redes de transportes y comunicaciones. (Monteserín, 2017, p. 241)

Del mismo modo, Monteserín por su lado también señala una situación parecida al caso de Aypate puesto que es toda una ciudadela conectada a una red vial inmensa, y puede ser que el reconocimiento de los valores patrimoniales pueda justificar la 
necesidad de establecer una gigantesca zona de protección, pero hacer eso sin aviso, sin consultarlo.

El "pacto patrimonialista" deja de lado a la población y al no ser parte del proceso, éstas se sienten excluidas de las decisiones que se toman con respecto al manejo de su territorio. Declarar Patrimonio Cultural de la Nación a más de cien mil hectáreas, sin un proceso participativo, causó conflictos y directamente, afecta a esta población que se caracteriza por practicar una economía de subsistencia, donde cada metro menos, significa menos comida.

Si bien en la fotografía panorámica se puede ver en la cima del cerro Aypate con infraestructura inca, existen poblaciones que rodean el sitio, y varios hogares se encuentran en constante conflicto con los agentes patrimonialistas, tanto por la prohibición del uso del territorio para actividades económicas como es la agricultura de subsistencia como para el libre tránsito.

\section{Superar el proceso de patrimonialización tradicional}

Continuar con prácticas que promueve el "pacto patrimonialista" tradicional no es viable, puesto que, según la teoría como la experiencia, queda demostrado que no funciona. Por ello, se considera necesario que los agentes patrimonialistas puedan reconocerse como gestores flexibles y abiertos a las necesidades y expectativas de la población, con el fin de fomentar una intervención que articule al territorio en su conjunto (naturaleza, cultura y población).

En el Perú, dentro de la gestión pública, en los últimos años, se puede evidenciar como la normativa nacional con respecto a la participación ha sufrido cambios, puesto que se reconoce que los derechos de la ciudadanía a la participación van más allá de los mecanismos representativos tradicionales, y con ello se han ampliado los mecanismos y oportunidades para ejercer derechos a la participación.

Se han establecido múltiples instrumentos de gestión y normas que promueven procesos participativos desde la Ley $\mathrm{N}^{\circ}$ 27806, Ley de Transparencia y Acceso a la Información (2002) hasta la Ley $N^{\circ}$ 29785, Ley de Consulta Previa a los Pueblos Indígenas u Originarios (2011), y ciertamente múltiples sectores cuentan con dispositivos legales, directivas, guías u otros, para llevar a cabo dichos procesos durante la intervención. Sin embargo, el sector responsable del patrimonio cultural, específicamente, las y los gestores del patrimonio cultural arqueológico, agentes patrimonialistas, no han demostrado interés en ejercer dicho marco o no han tenido la oportunidad de ejercerlo.

Aypate es uno de los múltiples sitios arqueológicos a lo largo del territorio nacional con población en o a sus alrededores. Algunas de estas poblaciones con continuidad histórica y otras con ocupaciones más recientes, en las que el proceso de patrimonialización tradicional no ha podido promover una convivencia o solución en armonía.

Ruiz (2018) señala que dicha gestión tradicional o perspectiva de acción hegemónica se caracteriza por cuatro estrategias: primero, "la monumentalización y la puesta en valor" que se preocupa por resaltar aspectos arquitectónicos monumentales y creer prejuiciosamente que ello, automáticamente promoverá una actitud favorable de la población; segundo, "la abstracción de la institucionalidad académica" que consistiría en ser parte de la academia y escribir para ella, sin preocuparse por promover mayor conocimiento en la población; tercero, "reacción punitiva" se refiere al establecimiento de sanciones, multas para evitar los delitos contra el patrimonio.

Por último, "la sensibilización difusionista unilateral" que consiste en implementar actividades informativas o educativas para "hacer entender" a la población sobre la 
importancia del bien cultural. Además, esta última tiene una carga peyorativa, de discriminación racial y étnica, puesto que se obvia los conocimientos, el patrimonio cultural inmaterial de dichas poblaciones.

Justamente para el caso del Qhapaq Ñan, el mismo autor señala la importancia de superar la gestión patrimonial tradicional y empezar a involucrar a las poblaciones en los procesos de toma de decisiones sobre el patrimonio cultural que se encuentra en su territorio.

(...) en cuanto la gestión patrimonial tradicional, no ha mostrado mayor preocupación en involucrar democráticamente a las comunidades y, por tanto, se carecía y, aún se carece, de normativas, mecanismos, metodologías y conceptos institucionalizados para abordar una labor hacia ese fin. La gestión del patrimonio cultural hegemónica todavía se orienta a partir de conceptos producidos en otras realidades y bajo la perspectiva unilateral y vertical del ente rector y la academia. Además, estas comunidades se encuentran en una situación socioeconómica complicada al ubicarse comúnmente entre las que tienen el Índice de Desarrollo Humano más bajo del país y, en donde, las políticas de desarrollo estatales en muchas ocasiones producen conflictos sociales. (Ruiz, 2018, p. 2)

Por ello en el año 2012, al estudiar la intervención del Proyecto Qhapaq Ñan se puede reconocer tres cambios, ciertamente innovadores para un agente patrimonialista. Estos cambios son los siguientes: (i) Contar con personal dedicado a actividades socioculturales en cada proyecto; (ii) Crear el Área de Participación Comunitaria; y (iii) Definir un nuevo enfoque de trabajo para la gestión del patrimonio cultural, llamado la puesta en uso social.

Se considera, en parte, que estos cambios facilitaron el ingreso del equipo técnico del Proyecto Qhapaq Ñan a la provincia de Ayabaca con la finalidad de implementar el Proyecto de Investigación Arqueológica de Aypate.

Así mismo, el cambio más importante para superar la gestión tradicional sería el nuevo enfoque de trabajo llamado la puesta en uso social del patrimonio cultural, que se concibe como una redefinición de la gestión patrimonial.

La definición creada por el Área de Participación Comunitaria del Proyecto Qhapaq Nan es la siguiente:

La puesta en uso social es el proceso dialógico y democrático que busca proteger, conservar y promover los bienes culturales materiales e inmateriales de manera participativa, buscando su reconstitución como elemento trascendente para el desarrollo sustentable de las comunidades. (Proyecto Qhapaq Nan, 2013)

En la práctica, esta concepción se enmarca en tres lineamientos de política:

a. Generación procesos de diálogo para reconocer intereses comunes y establecer consensos para el desarrollo de acciones conjuntas;

b. Desarrollo de un proceso participativo de planificación; e

c. Implementación de un proceso de gestión concertada para el desarrollo sustentable de las comunidades vinculadas.

Este nuevo enfoque y sus lineamientos, presentados en el Plan Cuatrienal 2012-2015, se considera innovador al promover directamente la vinculación entre la gestión del patrimonio cultural con el desarrollo de las comunidades.

Ciertamente, dicho enfoque redefine la gestión del patrimonio cultural al encaminar los esfuerzos por gestionar de una manera participativa que permita reconocer los intereses comunes para llevar a cabo una planificación participativa y así promover 
un proceso de gestión concertada, con el fin de reconstituir al patrimonio como un elemento trascendente para el desarrollo de las poblaciones.

Pero, de acuerdo a los documentos revisados contar con estos cambios, si bien es un buen comienzo, no fue sencillo y se necesitó de tiempo y paciencia para reestablecer lazos de confianza con las rondas y comunidades campesinas de la provincia de Ayabaca.

Tabla $\mathbf{N}^{\circ}$ 1. Acontecimientos importantes del proceso participativo

\begin{tabular}{cc}
\hline Año & Acontecimiento \\
\hline 2012 & Participación en asambleas comunales \\
2013 & Participación en asambleas comunales \\
2014 & Taller de diagnóstico comunitario participativo \\
2014 & Organización conjunta de la celebración por la inscripción del Qhapaq Nan a la Lista de Patrimonio \\
2016 & Mundial de la Unesco
\end{tabular}

Elaboración propia. Fuente: Archivo del PQÑ.

Como se puede evidenciar en la tabla $\mathrm{N}^{\circ} 1$, los dos primeros años de intervención fueron de diálogo. El equipo técnico del Área de Participación Comunitaria participaba de manera constante en los espacios de toma de decisiones de las comunidades y rondas campesinas, las asambleas comunales; en las que eran invitados para poder exponer los objetivos del Proyecto, así como para informar del proceso de nominación del Qhapaq Nan para su postulación a la Lista de Patrimonio Mundial de la Unesco.

Luego, en el 2014 se inició con la planificación participativa de la intervención, en la cual se ejecutó un diagnóstico participativo para el reconocimiento de necesidades y expectativas de la población y la organización conjunta de la celebración por la inscripción del Qhapaq Nan a la Lista de Patrimonio Mundial de la Unesco(Ver Figura 3).

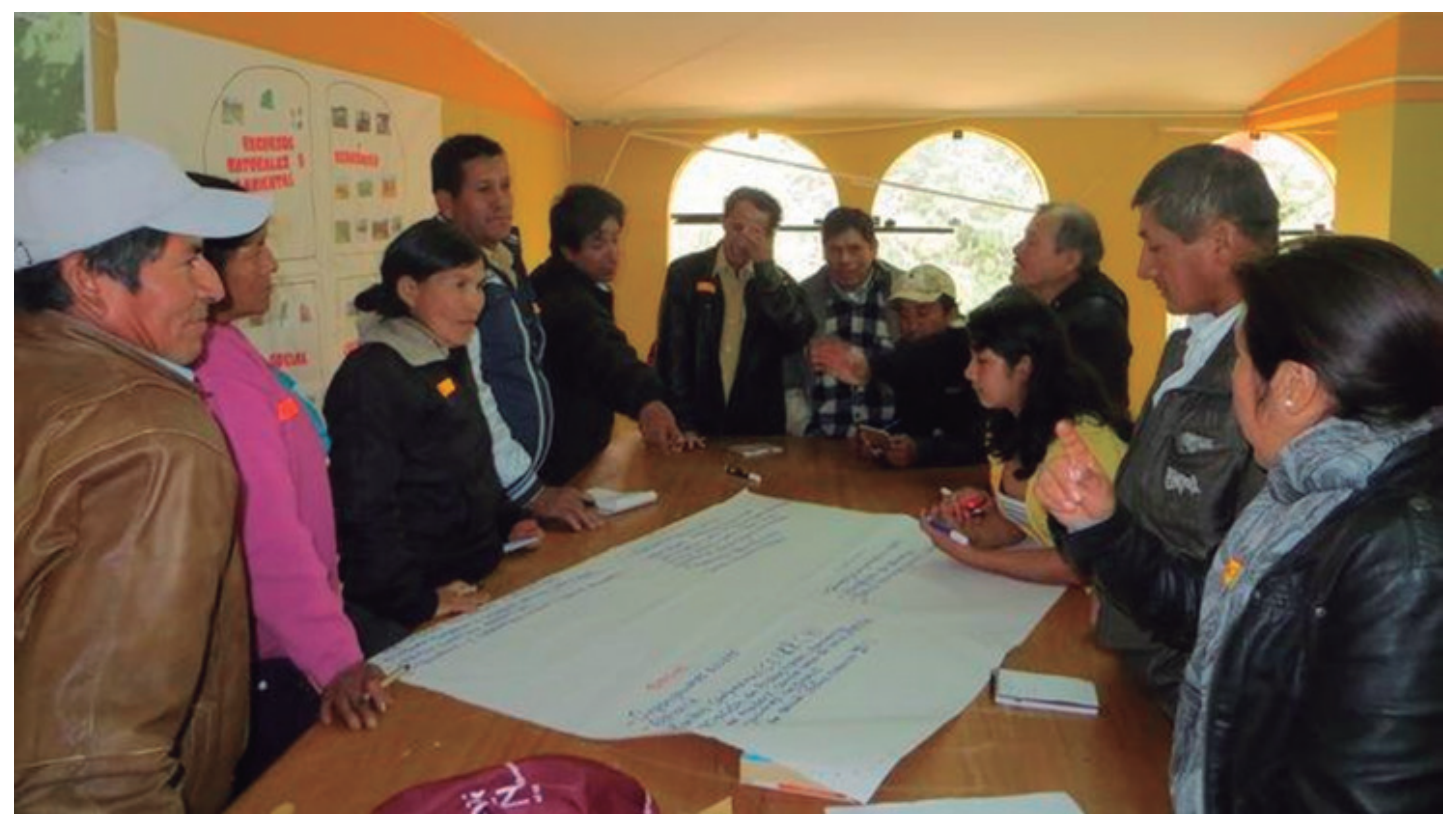

Figura $\mathbf{N}^{\circledR} 3$. Diagnóstico participativo con representantes comunales de Ayabaca

Fuente: PQÑ (s.f.)

Finalmente, se evaluó la intervención y se validó de manera participativa el proceso, con todo ello, se puede decir que se siguió con el enfoque de la puesta en uso social y sus lineamientos de política (Ver Figura 4). 


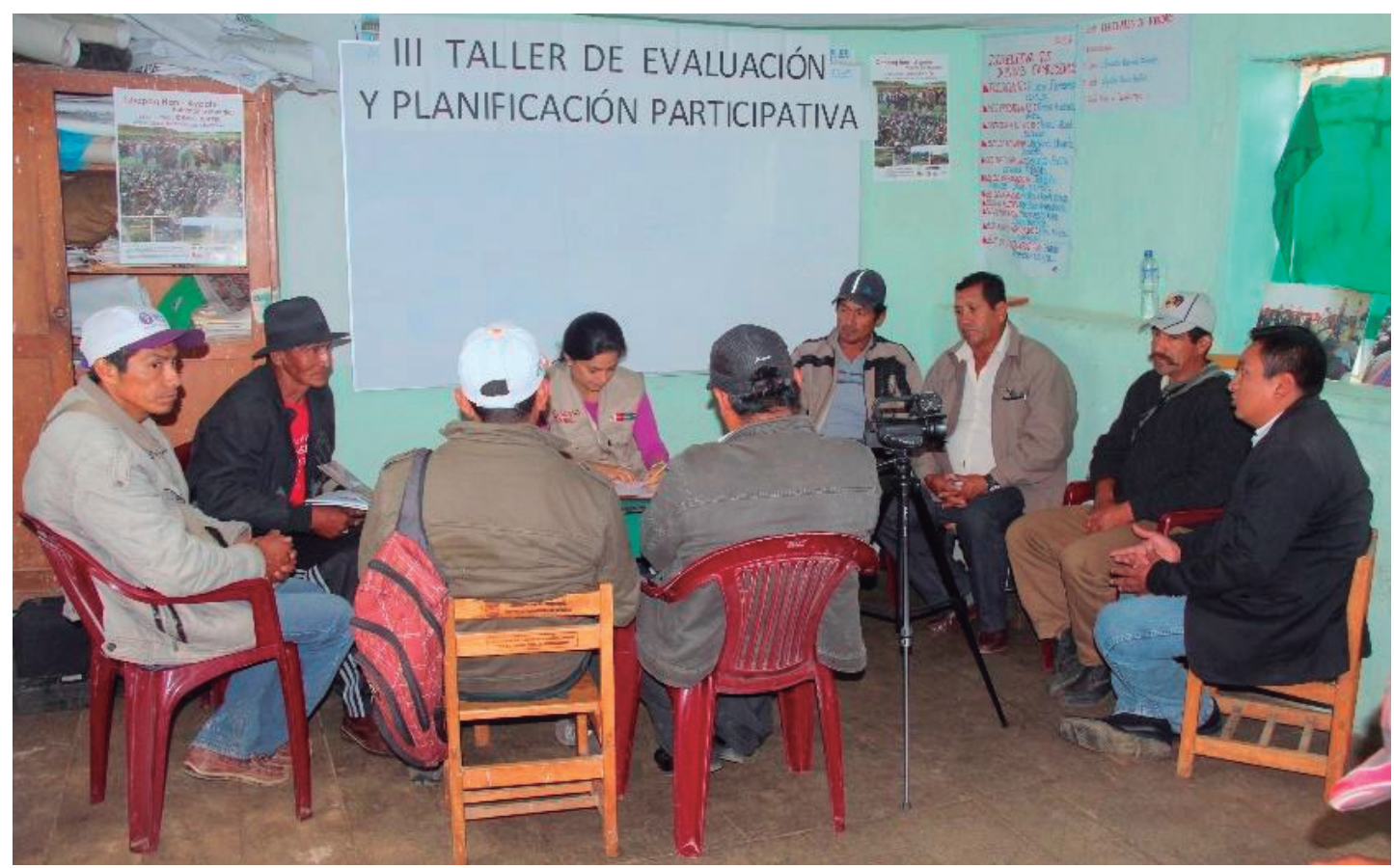

Figura $\mathbf{N}^{\circ}$ 4. Grupo focal con autoridades comunales de Ayabaca

Fuente: $\mathrm{PQN \tilde {N }}$ (s.f.)

Con todo lo anterior, se puede señalar que lo construido durante el periodo del 2012 al 2016, ha sido un trabajo constante de apertura, trato horizontal, respeto a las formas propias y tiempos de toma de decisiones de las comunidades y rondas campesinas.

Sin embargo, es también un trabajo que puede resquebrajarse con mucha facilidad, los actores patrimonialistas interesados en gestionar dicho sitio arqueológico deben tener presente que construir lazos de confianza es una tarea difícil. Incluso, más difícil cuando se trata de recuperar dicha confianza (Ver Figura 5).

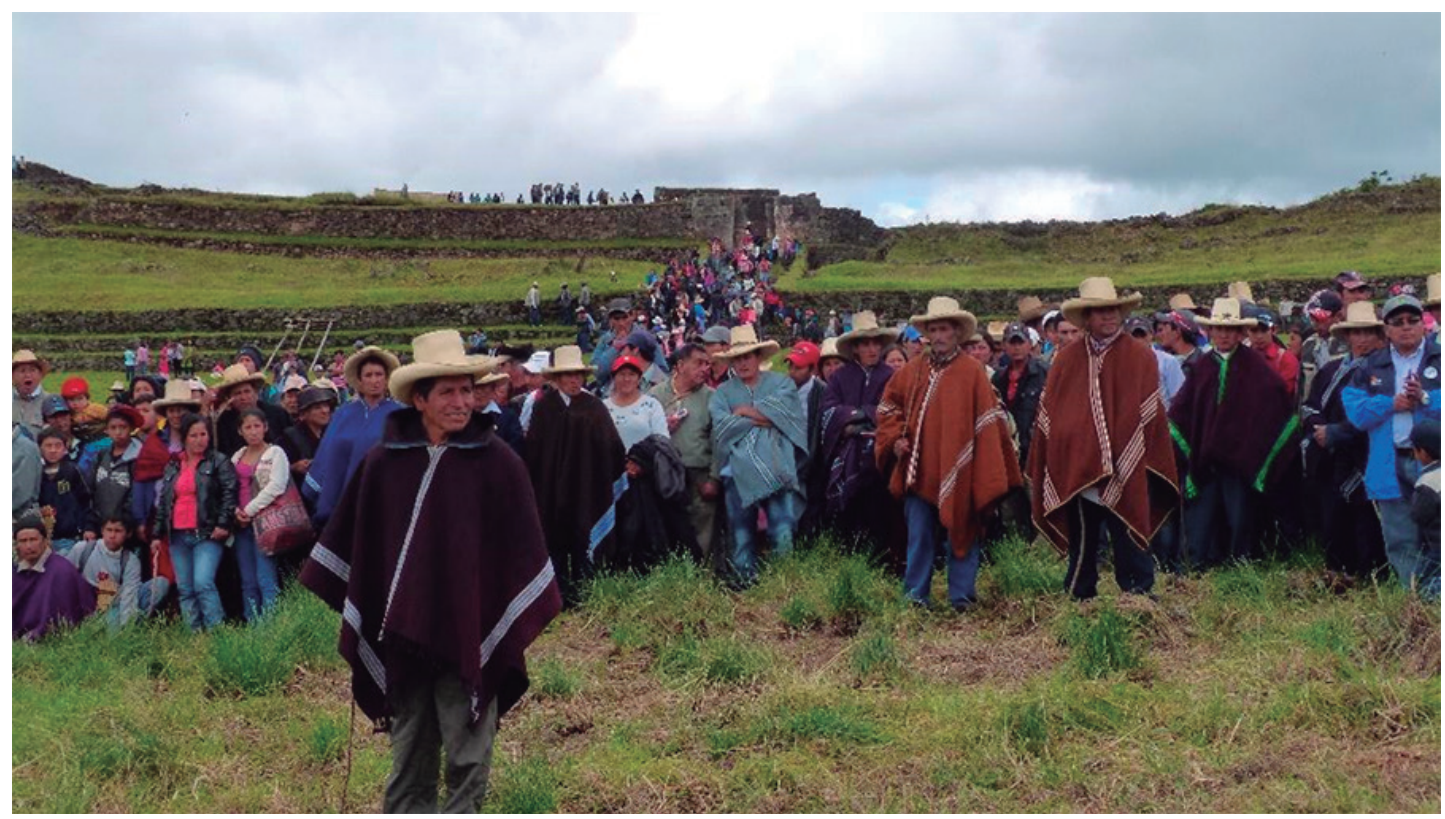

Figura $\mathbf{N}^{\circ}$ 5. Presidente de la FEPROCCA como anfitrión de la Celebración por la inscripción del Qhapaq Ñan a la Lista de Patrimonio Mundial de la Unesco.

Fuente: PQÑ (s.f.) 


\section{Reflexiones finales}

El presente artículo tuvo como finalidad presentar el contexto social y aproximaciones del proceso de patrimonialización del sitio arqueológico de Aypate, así como analizar las medidas, desde el Proyecto Qhapaq Ñan, que intentan redefinir la gestión tradicional del patrimonio cultural.

Tal como se aprecia párrafos arriba, el sitio arqueológico de Aypate ubicado en la región de Piura es un territorio rico en cultura y recursos naturales. Sin embargo, el contexto social no refleja esta riqueza, al contrario, se define por una alta vulnerabilidad social.

Justamente, el proceso de patrimonialización de Aypate y de las 156.061 hectáreas a la redonda declaradas como intangibles, refuerzan la situación de vulnerabilidad, puesto que se restringe el uso del territorio para la producción agropecuaria de autoconsumo.

Profundizando el distanciamiento por parte de la población con su patrimonio, puesto que ejecutar medidas administrativas que caracterizan al proceso de patrimonialización, sin hacer un llamado a la ciudadanía para que se informen e incluso mejor, para que formen parte del proceso de toma de decisiones, teniendo en cuenta que es un territorio donde existe una organización social bien estructurada a nivel comunal, crea conflicto social.

Los procesos de patrimonialización tradicionales, en escenarios donde existen diversas necesidades como la falta de servicios básicos, incluso peor, en un contexto rural, donde el principal bien con el que cuenta la población es la tierra, y al declararla como intangible, se le restringe el desarrollo de actividades económicas que permite a estas personas subsistir, es pues, despojarlas del medio que necesitan para mantenerse vivas, interrumpiendo así cualquier iniciativa que promueva el desarrollo sostenible del territorio.

Un camino para promover un cambio en el proceso de patrimonialización tradicional es la implementación de mecanismos participativos, en este caso se puede evidenciar que la puesta en uso social del patrimonio cultural y sus lineamientos de políticas han dado frutos.

Según la información recopilada, el proceso no ha sido fácil, ni ha sido un proceso rápido, se ha necesitado de tiempo, y este proceso empieza, teniendo la intención de conocer la historia del territorio con respecto a los conflictos históricos que han acontecido, específicamente en la gestión del patrimonio cultural.

Escuchar los reclamos de los actores involucrados que en este caso específico tomo dos años de diálogo (2012-2014), en el cual los agentes patrimonialistas han participado en los espacios propios de toma de decisiones de las comunidades como lo son las asambleas comunales, al comienzo brindando información, en general, sobre la intervención arqueológica en sí misma y, posteriormente contando las intenciones del Proyecto Qhapaq Nan en el territorio comunal.

Para luego, iniciar con una gestión participativa, definida como la puesta en uso social del patrimonio cultural, la cual, según el horizonte temporal de esta investigación, se registró del año 2014 al 2016. Del mismo modo, es importante reconocer que este proceso como todo proceso participativo no es estático y puedo avanzar como retroceder, todo dependerá del tipo de gestión que se lleve a cabo. Sin embargo, se espera que continúen los esfuerzos por superar el proceso de patrimonialización tradicional y el pacto patrimonialista que ha sufrido y sufre nuestro país.

\section{Referencias Bibliográficas}

Asensio, R. (julio de 2013). ¿De qué hablamos cuando hablamos de participación comunitaria en la gestión del patrimonio cultural? Argumentos, 7 (3), 25-33. Recuperado el 26 de febrero de 2019 de http://www.revistargumentos.org.pe/participacion_patrimonio.html 
Astuhuamán, C. (2013). El patrimonio arqueológico en la Región Piura: investigación, registro y gestión de los sitios y camino inca. Compartiendo el patrimonio; Paisajes culturales y modelos de gestión en Andalucía y Piura, 183-214.

Google. (s.f.). [Mapa de Ayabaca, Piura, Perú en Google maps]. Recuperado el 28 de Abril, 2020, de https://www.google.com/maps/place/Aypate

Grupo técnico de Diversidad Biológica del Gobierno Regional de Piura. (2012). Estrategia Regional y Plan de Acción para la Conservación de la Diversidad Biológica de la región Piura. Recuperado el 19 de marzo de 2020, desde https://www.cbd.int/doc/nbsap/sbsap/pesbsap-piura-es.pdf

Hernández, R., Fernández, C., \& Baptista, M. (2010). Metodología de la investigación (Quinta edición ed.). McGRAW-HILL. Recuperado el 29 de Abril de 2020 de https://www.esup.edu. pe/descargas/dep_investigacion/Metodologia\%20de\%20la\%20investigaci\%C3\%B3n\%20 5ta\%20Edici\%C3\%B3n.pdf

INEI. (2017). Censo Nacionales 2017- XII de Población, VII de Vivienda y III de Comunidades Indígenas del año 2017. Recuperado el 26 de marzo de 2013, de http://censo2017.inei.gob.pe/

INEI. (2018). Piura. Resultados Definitivos. Tomo I. Recuperado el 26 de marzo de 2020, de https://www.inei.gob.pe/media/MenuRecursivo/publicaciones_digitales/Est/ Lib1553/20TOMO_01.pdf

Marcone, G., y Ruiz, R. (2014). Qhapaq Ñan: el reto del uso social del patrimonio cultural. Quehacer, 195, 114-121.

Monteserín, O. (2017). Reseñas de F, Manero y J, García, J. (Coords.). Patrimonio cultural y desarrollo territorial. Geografía Norte Grande. 67. 241-245. Recuperado el 19 de marzo de 2020 de https://scielo.conicyt.cl/pdf/rgeong/n67/art13.pdf

Morán, J. (2018). Una propuesta de evaluación participativa que aporte a la iniciativa de Gobierno Abierto: El caso del Qhapaq Nan. Estudios Políticos. Memoria del 56. Congreso Internacional de Americanista, 291-299.

Municipalidad Provincial de Ayabaca. (2012). Plan de Desarrollo Concertado de la Provincia de Ayabaca. Recuperado el 10 de marzo de 2020 de https://www.peru.gob.pe/docs/ PLANES/12172/PLAN_12172_Plan_de_Desarrolo_Concertado_2012.pdf

Proyecto Qhapaq Ñan. (2013). Plan Cuatrienal 2012-2015. Documento de trabajo.

Proyecto Qhapaq Nan. (s.f.). [Noticias del Proyecto Qhapaq Nan]. Recuperado el 28 de Abril, 2020, de https://qhapaqnan.cultura.pe/noticias

Ruiz, R. (2018). La Participación Comunitaria para la Puesta en Uso Social del Patrimonio Mundial: Una experiencia conceptual y práctica con las comunidades asociadas al Qhapaq Ñan. Actas del III Congreso Internacional de Buenas Prácticas en Patrimonio Mundial: Acciones Integrales, 142-159. 